\title{
Toward research-tested mobile health interventions to prevent diabetes and cardiovascular disease among persons with pre- diabetes
}

\author{
Steven S. Coughlin ${ }^{1,2}$, Jessica Lynn Stewart ${ }^{1}$ \\ ${ }^{1}$ Department of Clinical and Digital Health Sciences, College of Allied Health Sciences, Augusta University, Augusta, GA, USA; ${ }^{2}$ Research Service, \\ Charlie Norwood Veterans Affairs Medical Center, Augusta, GA, USA \\ Contributions: (I) Conception and design: SS Coughlin; (II) Administrative support: SS Coughlin; (III) Provision of study materials or patients: All \\ authors; (IV) Collection and assembly of data: None; (V) Data analysis and interpretation: All authors; (VI) Manuscript writing: All authors; (VII) \\ Final approval of manuscript: All authors. \\ Correspondence to: Dr. Steven S. Coughlin, PhD. Department of Clinical and Digital Health Sciences, College of Allied Health Sciences, Augusta \\ University, 1120 15th Street, EC-4324, Augusta, GA 30912, USA. Email: scoughlin@augusta.edu.
}

\begin{abstract}
Background: About $35 \%$ of US adults have pre-diabetes and an increased risk of diabetes. Consumerfacing devices such as the Fitbit help users become more physically active and manage their weight which reduces risk of diabetes and cardiovascular disease.

Methods: In this commentary we provide a summary of healthy lifestyle intervention studies involving persons with pre-diabetes including those conducted in routine clinical practice. We also provide an account of how such interventions might be enhanced through the use of wearable devices linked to smartphone applications.

Results: In initial trials focusing on overweight and obesity, consumer wearable devices have been shown to increase physical activity and reduce weight. However, the acceptability and effectiveness of these mHealth interventions among persons with impaired glucose tolerance or impaired fasting glucose is unknown; studies involving persons with pre-diabetes have not yet been reported.

Conclusions: Research is needed to determine the feasibility and efficacy of wearable devices in improving physical activity and weight management in persons with pre-diabetes who are at-risk of diabetes and cardiovascular disease.
\end{abstract}

Keywords: Impaired fasting glucose; impaired glucose tolerance; obesity; physical activity; pre-diabetes; randomized controlled trials; smartphone applications; weight loss

Received: 18 October 2017; Accepted: 30 October 2017; Published: 15 November 2017.

doi: $10.21037 /$ jhmhp.2017.11.02

View this article at: http://dx.doi.org/10.21037/jhmhp.2017.11.02

In 2015 , there were an estimated 415 million adults aged 20-79 years living with diabetes world-side (1). An additional 318 million adults had impaired glucose tolerance. Approximately $9.4 \%$ of the US population has diabetes and the prevalence is expected to reach $25 \%$ by $2050(2,3)$. About $35 \%$ of US adults have pre-diabetes with a four-fold increased risk of progressing to diabetes compared to those who are normoglycemic (4). Persons with diabetes are at-risk of macrovascular and microvascular complications (5). Sedentary behavior, physical inactivity, and poor diet and nutrition are important public health issues that contribute to the population burden of diabetes (6). In the US, about one-third of adults are physically inactive and about $35 \%$ of adults are obese (6-8). Elevated rates of diabetes and obesity and associations of diabetes and obesity with cardiovascular disease and certain cancers have increased interest in identifying effective ways to improve physical activity, diet, and 
nutrition.

Impaired glucose tolerance is an intermediate condition between normal glucose tolerance and overt diabetes; persons with impaired glucose tolerance are at-risk of type 2 diabetes (5). Results from randomized controlled trials conducted in the US, Finland, Sweden, Japan, and China indicate that intensive lifestyle interventions can reduce the risk of progression to diabetes in persons with impaired glucose tolerance or impaired fasting glucose (5,9-11). Lifestyle changes were also shown to have a beneficial effect on hypertension and hyperlipidemia (5). The interventions tested in the trials have consisted of structured, interventions focused on encouraging physical activity and improved dietary intake through counseling, goal-setting, providing feedback, and monitoring at-risk participants $(9,10)$. These interventions have shown that weight loss $\geq 3.5 \mathrm{~kg}$ can be achieved with lifestyle interventions and that the incidence rate of new-onset diabetes can be lowered by $30 \%$ to $58 \%$ $(5,12)$. Substantial reduction in diabetes risk was seen with modest weight loss and increased physical activity. Results from the trials indicate that caloric restriction, physical activity, and behavioral support are effective in improving glucose tolerance and preventing or delaying the onset of diabetes. In the Diabetes Prevention Program in the US, a $34 \%$ reduction in incidence of diabetes was sustained for 10 years following the intervention (11).

Increasing efforts have been made to translate the intensive, structured interventions tested in these trials into primary care where there are constraints on resources and time (13-20). Primary care providers often deal with competing health priorities in their practice including pre-diabetes and a variety of other health conditions. Primary care providers are increasingly called upon to address multiple health care problems during health care visits. Cardona-Morrell et al. (12) conducted a systematic review of randomized controlled trials, before/after evaluations, and cohort studies of lifestyle interventions to reduce diabetes risk conducted in routine clinical settings and delivered by healthcare providers. The patients recruited in the studies were at high-risk of diabetes based upon impaired glucose tolerance, obesity, metabolic syndrome, or a combination of these. In some of the studies reviewed, researchers modified intensive, structured interventions that had been found to be effective in randomized controlled trials by shortening the duration of program, delivering group sessions rather than individual one-on-one counseling, and reducing one-on-one or group counseling sessions (12). A positive intervention effect on weight was observed in all of the studies. A metaanalysis of results from four of the studies showed that the lifestyle interventions in clinical settings had a positive effect on weight after one year but no effect on physiologic measures (12).

Mobile health (mHealth) technologies provide opportunities in patients with pre-diabetes to assist in preventing or reducing progression to diabetes through increased physical activity and healthy diet and nutrition (21-24). Examples of wearable technology include Fitbit and Jawbone devices, where users can measure a variety of activity-related outcomes including steps, distance, flights of stairs, active minutes, heart rate, and calories. Additionally, smartphone app and web interfaces attached to wearable devices allow users to compete in group challenges and socialize with friends. Several studies have utilized Fitbit devices in lifestyle interventions to increase physical activity and reduce obesity (22,25-33). Research on the use of consumer-directed wearable devices to promote and monitor physical activity in pre-diabetic persons is limited. There are several advantages to incorporating wearable devices in healthy lifestyle interventions. In many instances, the resource-intensive and time-consuming methods of established interventions for physical activity and weight loss limit full participation and widespread dissemination. Additionally, costs associated with wearable devices for monitoring physical activity are often less than several types of exercise equipment or becoming a member of a gym (34). There are several wearable devices available to consumers that monitor and track physical activity, and sales of these wearable devices are projected to exceed 82 million by 2019 (35).

There is limited research on the use of smartphone technology applications to promote and track physical activity in at-risk pre-diabetic populations (36-39). The diabetes and technology for increased activity (DaTA) pilot study consisted of an 8-week intervention in which participants with two or more risk factors for metabolic syndrome were given Blackberry smartphones and pedometers $(36,37)$. The technology allowed self-monitoring of physical activity and resulted in improvements in daily physical activity, along with a better overall awareness of how healthy lifestyle changes impact health outcomes $(36,37)$. The same technology was used in a randomized controlled trial of patients at-risk for cardiovascular disease and type 2 diabetes mellitus $(n=149)$, in which both a control and intervention group received exercise instruction, while the intervention group was 
also provided with smartphones equipped with a mHealth application and pedometers $(38,39)$. The intervention group showed small, but significant, decreases in hemoglobin A1c (HbA1c) at 24 and 52 weeks, while the active control group showed more transient HbA1c decreases at 24 weeks (39). No significant differences were observed between groups at 24 or 52 weeks (39).

Studies are needed to examine the efficacy of wearable devices in improving physical activity and weight management among persons with impaired glucose tolerance or impaired fasting glucose who are at-risk of diabetes and cardiovascular disease. To clarify the efficacy of wearable devices for increasing physical activity among persons with pre-diabetes, studies with a randomized controlled trial design are needed that have adequate sample sizes and study periods.

\section{Acknowledgments}

Funding: None.

\section{Footnote}

Conflicts of Interest: Both authors have completed the ICMJE uniform disclosure form (available at http://dx.doi. org/10.21037/jhmhp.2017.11.02). SSC serve as an unpaid Associate Editor of Fournal of Hospital Management and Health Policy. The other author has no conflicts of interest to declare.

Ethical Statement: The authors are accountable for all aspects of the work in ensuring that questions related to the accuracy or integrity of any part of the work are appropriately investigated and resolved.

Open Access Statement: This is an Open Access article distributed in accordance with the Creative Commons Attribution-NonCommercial-NoDerivs 4.0 International License (CC BY-NC-ND 4.0), which permits the noncommercial replication and distribution of the article with the strict proviso that no changes or edits are made and the original work is properly cited (including links to both the formal publication through the relevant DOI and the license). See: https://creativecommons.org/licenses/by-nc-nd/4.0/.

\section{References}

1. International Diabetes Federation. IDF Diabetes Atlas. 7th ed. Brussels, Belgium: International Diabetes Federation, 2015. Available online: http://www.diabetesatlas.org

2. National Diabetes Statistics Report: estimates of diabetes and its burden in the United States, 2017. Atlanta, GA: Centers for Disease Control and Prevention, 2014.

3. Boyle JP, Thompson TJ, Gregg EW, et al. Projection of the year 2050 burden of diabetes in the US adult population: dynamic modeling of incidence, mortality, and prediabetes prevalence. Popul Health Metr 2010;8:29.

4. Bullard KM, Saydah SH, Imperatore G, et al. Secular changes in US prediabetes prevalence defined by hemoglobin A1c and fasting plasma glucose: National Health and Nutrition Examination Surveys, 1999-2010. Diabetes Care 2013;36:2286-93.

5. Tuomilehto J, Lindstrom J, Eriksson JG, et al. Prevention of type 2 diabetes mellitus by changes in lifestyle among subjects with impaired glucose tolerance. N Engl J Med 2001;344:1343-50.

6. Rabin C, Bock B. Desired features of smartphone applications' promoting physical activity. Telemed J E Health 2011;17:801-3.

7. Johnson NB, Hayes LD, Brown K. CDC National Health Report: leading causes of morbidity and mortality and associated behavioral risk and protective factors-United States, 2005-2013. MMWR Suppl 2014;63:3-27.

8. Dietz WH. The response of the US Centers for Disease Control and Prevention to the obesity epidemic. Annu Rev Public Health 2015;36:575-96.

9. Li G, Zhang P, Wang J, et al. The long-term effect of lifestyle interventions to prevent diabetes in the China Da Qing Diabetes Prevention Study: a 20-year follow-up study. Lancet 2008;371:1783-9.

10. Lindström J, Ilanne-Parikka P, Peltonen M, et al. Sustained reduction in the incidence of type 2 diabetes by lifestyle intervention: follow-up of the Finnish Diabetes Prevention Study. Lancet 2006;368:1673-9.

11. Knowler WC, Fowler SE, Hamman RF, et al. 10-year follow-up of diabetes incidence and weight loss in the Diabetes Prevention Program Outcomes Study. Lancet 2009;374:1677-86.

12. Cardona-Morrell M, Rychetnik L, Morrell SL, et al. Reduction in diabetes risk in routine clinical practice: are physical activity and nutrition interventions feasible and are the outcomes from reference trials replicable? A systematic review and meta-analysis. BMC Public Health 2010;10:653.

13. Messina J, Campbell S, Morris R, et al. A narrative systematic review of factors affecting diabetes prevention 
in primary care settings. PLoS One 2017;12:e0177699.

14. Ma J, Yank V, Xiao L, et al. Translating the Diabetes Prevention Program lifestyle intervention for weight loss into primary care. JAMA Intern Med 2013;173:113-21.

15. Cloney TA, Galer-Unti RA, Barkley WM. Provider practices in prediabetes intervention and diabetes prevention: application of evidence-based research in the medical office setting. J Prim Care Community Health 2011;2:187-91.

16. Whittemore R, Melkus G, Wagner J, et al. Translating the Diabetes Prevention Program to primary care. Nurs Res 2009;58:2-12.

17. Duijzer G, Janset SC, Haveman-Nies A, et al. Translating the SLIM diabetes prevention intervention into SLIMMER: implications for the Dutch primary health care. Fam Pract 2012;29 Suppl 1:1145-52.

18. Brunisholz KD, Kim J, Savitz LA, et al. A formative evaluation of a diabetes prevention program using the REAIM framework in a learning health care system, Utah, 2013-2015. Prev Chronic Dis 2017;14:E58.

19. Gilis-Januszewska A, Lindstrom J, Tuomilehto J, et al. Sustained diabetes risk reduction after real life and primary health care setting implementation of the diabetes in Europe prevention using lifestyle, physical activity and nutritional intervention (DE-PLAN) project. BMC Public Health 2017;17:198.

20. Vermunt PW, Milder IE, Wielaard F, et al. Implementation of a lifestyle intervention for type 2 diabetes prevention in Dutch primary care: opportunities for intervention delivery. BMC Family Practice 2012;13:79.

21. Wang JB, Cadmus-Bertram LA, Natarajan L, et al. Wearable sensor/device (Fitbit One) and SMS textmessaging prompts to increase physical activity in overweight and obese adults: A randomized controlled trial. Telemed J E Health 2015;21:782-92.

22. Cadmus-Bertram LA, Marcus BH, Patterson RE, et al. Randomized trial of a Fitbit-based physical activity intervention for women. Am J Prev Med 2015;49:414-8.

23. Cadmus-Bertram L, Marcus BH, Patterson RE, et al. Use of the Fitbit to Measure Adherence to a Physical Activity Intervention Among Overweight or Obese, Postmenopausal Women: Self-Monitoring Trajectory During 16 Weeks. JMIR Mhealth Uhealth 2015;3:e96.

24. Hartman SJ, Nelson SH, Cadmus-Bertram LA, et al. Technology- and phone-based weight loss intervention. Am J Prev Med 2016;51:714-21.

25. Martin SS, Feldman DI, Blumenthal RS, et al. mActive: a randomized clinical trial of an automated mHealth intervention for physical activity promotion. J Am Heart Assoc 2015;4. pii: e002239.

26. Yingling LR, Brooks AT, Wallen GW, et al. Community engagement to optimize the use of web-based and wearable technology in a cardiovascular health and needs assessment study: a mixed methods approach. JMIR Mhealth Uhealth 2016;4:e38.

27. Naslund JA, Aschbrener KA, Bartels SG. Wearable devices and smartphones for activity tracking among people with serious mental illness. Ment Health Phys Act 2016;10:10-7.

28. Hartman SJ, Nelson SH, Cadmus-Bertram LA, et al. Technology- and Phone-Based Weight Loss Intervention: Pilot RCT in Women at Elevated Breast Cancer Risk. Am J Prev Med 2016;51:714-21.

29. Wang JB, Cataldo JK, Ayala GX, et al. Mobile and wearable device features that matter in promoting physical activity. J Mob Technol Med 2016;5:2-11.

30. Ashe MC, Winters M, Hoppmann CA, et al. "Not just another walking program": Everyday Activity Supports You (EASY) model-a randomized pilot study for a parallel randomized controlled trial. Pilot Feasibility Stud 2015;1:1-12.

31. Choi J, Lee JH, Vittinghoff E, et al. mHealth physical activity intervention: a randomized pilot study in physically inactive pregnant women. Matern Child Health J 2016;20:1091-101.

32. Chung AE, Skinner AC, Hasty SE, et al. Tweeting to health: a novel mHealth intervention using Fitbits and Twitter to Foster healthy lifestyles. Clin Pediatr (Phila) 2016. [Epub ahead of print].

33. Jakicic JM, Davis KK, Rogers RJ, et al. Effect of Wearable Technology Combined With a Lifestyle Intervention on Long-term Weight Loss: The IDEA Randomized Clinical Trial. JAMA 2016;316:1161-71.

34. Coughlin SS, Stewart J. Use of Consumer Wearable Devices to Promote Physical Activity: A Review of Health Intervention Studies. J Environ Health Sci 2016;2.

35. Parks Associates. Global sales of connected digital fitness trackers will exceed 82 million in 2019. Dallas, TX: AARP, Citi, Khosla Ventures, McKesson Ventures, and Norwest Venture Partners to Discuss "Investing in the Connected Health Market" at Connected Health Summit, 2015.

36. Stuckey M, Fulkerson R, Read E, et al. Remote monitoring technologies for the prevention of metabolic syndrome: the Diabetes and Technology for Increased Activity (DaTA) study. J Diabetes Sci Technol 2011;5:936-44.

37. Stuckey M, Russell-Minda E, Read E, et al. Diabetes 
and Technology for Increased Activity (DaTA) study: results of a remote monitoring intervention for prevention of metabolic syndrome. J Diabetes Sci Technol 2011;5:928-35.

38. Stuckey MI, Shapiro S, Gill DP, et al. A lifestyle intervention supported by mobile health technologies to

doi: $10.21037 /$ jhmhp.2017.11.02

Cite this article as: Coughlin SS, Stewart JL. Toward researchtested mobile health interventions to prevent diabetes and cardiovascular disease among persons with pre-diabetes. J Hosp Manag Health Policy 2017;1:7. improve the cardiometabolic risk profile of individuals at risk for cardiovascular disease and type 2 diabetes: study rationale and protocol. BMC Public Health 2013;13:1051.

39. Petrella RJ, Stuckey MI, Shapiro S, et al. Mobile health, exercise and metabolic risk: a randomized controlled trial. BMC Public Health 2014;14:1082. 